\title{
PRISÃO CIVIL DO DEVEDOR DE ALIMENTOS: UMA MEDIDA INEFICAZ?
}

\author{
Bruno Nascimento de Couto
}

Universidade do Oeste Paulista - UNOESTE, curso de Direito, Presidente Prudente, SP. E-mail: bruno.cnasc@gmail.com

\section{RESUMO}

O presente trabalho tem por objetivo apresentar uma reflexão sobre a única modalidade de prisão civil prevista no ordenamento jurídico nacional, as causas que justificam sua decretação e seu procedimento. Para tanto, estudar-se-á o estatuto da prisão, apresentando sua origem e finalidade, bem como o instituto dos alimentos previsto no Código Civil, estabelecendo sua destinação e a sua finalidade, e como deverá ser prestado. A pesquisa constou de pesquisas bibliográficas e artigos eletrônicos. Os dados foram analisados pelo método hipotético-dedutivo. Por fim, analisar-se-á o diploma processual civil no que tange à prisão civil, apontando como se dá sua decretação e as causas que a justificam, bem como seu procedimento. Conclui-se que a prisão civil é uma das formas de repressão ao devedor de alimentos, e que deve ser reformulada em face de sua ineficácia.

Palavras-chave: Processo civil, Prisão civil, Débitos alimentares, Alimentos, Desemprego.

\section{CIVIL PRISION OF THE MAITENANCE DEBTOR: NA INEFFECTIVE MEASURE?}

\begin{abstract}
The present work aims to present a reflection on the only modality of civil imprisonment foreseen in the national juridical order, the causes that justify its decree and its procedure. In order to do so, it will study the prison's statute, presenting its origin and purpose, as well as the food institute established in the Civil Code, establishing its destination and its purpose, and how it should be provided. The research consisted of bibliographical researches and electronic articles. Data were analyzed using the hypothetico-deductive method. Finally, we will analyze the civil procedural law regarding the civil prison, pointing out how its decree is given and the causes that justify it, as well as its procedure. It is concluded that civil prison is one of the forms of repression of the maintenance debtor, and that it must be reformulated in the face of its ineffectiveness.
\end{abstract}

Keywords: Civil lawsuit, Civil Prison, Foodstuffs, Foods, Unemployment.

\section{INTRODUÇÃO}

Os últimos anos do século XX foram consagrados como a era de ouro das commodities que, em linhas gerais, consistem em produtos que não sofreram, até então, alguma modificação que altere a sua forma original, a sua forma in natura, o que seria um exemplo para o cenário nacional, como o café ou até mesmo o petróleo.

O que os especialistas chamam de boom das commodities, impulsionou a economia nacional entre os anos 2000 e 2010, gerando mais empregos e atribuindo uma maior renda às pessoas de baixa renda. Fato é que o PIB na época demonstrou crescimento de 7,5\%, sendo considerado a maior expansão desde 1986Contudo o mercado brasileiro não conseguiu concorrer com a economia emergente da China, o que o levou a um aumento nos preços e consequentemente um aumento na taxa dos juros. 
Somada aos escândalos de corrupção, de conhecimento notório, a bolha formada pela valorização dos commodities estourou. Hoje, o índice de desemprego atinge 12,8 \% da população nacional, segundo as estatísticas lançadas pelo Governo Federal, de repercussão na mídia, na última semana de julho de $2017^{1}$, o que vem acarretando um maior número de inadimplentes.

A inadimplência, por atingir várias esferas sociais e econômicas, também atinge os devedores de alimentos. Como, via de regra, os alimentos devem ser prestados mês a mês, na medida em que há o atraso no pagamento das prestações alimentícias, além dos juros incidente, nasce o direito ao alimentando de propor uma demanda para cobrar do alimentante as prestações vencidas. No caso em tela, como o enfoque é abordar a prisão civil, justifica-se a demanda, segundo a súmula 309 , do STJ, in verbis:

O débito alimentar que autoriza a prisão civil do alimentante é o que compreende as três prestações anteriores ao ajuizamento da execução e as que se vencerem no curso do processo. (BRASIL, 2006)

Assim, instaurada a demanda e caracterizado o menoscabo do devedor de alimentos, o juiz poderá fixar a prisão civil, que de acordo com o art. 528, será de 01 a 03 meses, vejamos (BRASIL, 2015):

Art. 528. No cumprimento de sentença que condene ao pagamento de prestação alimentícia ou de decisão interlocutória que fixe alimentos, o juiz, a requerimento do exequente, mandará intimar o executado pessoalmente para, em 3 (três) dias, pagar o débito, provar que o fez ou justificar a impossibilidade de efetuá-lo.

[...]

$\S 3^{\circ}$ Se o executado não pagar ou se a justificativa apresentada não for aceita, o juiz, além de mandar protestar o pronunciamento judicial na forma do $\S 1^{\circ}$, decretar-lhe-á a prisão pelo prazo de 1 (um) a 3 (três) meses.

No entanto, esqueceu-se o legislador que o instituto da prisão visa à privação de liberdade do alimentante devedor, e que ao enclausurá-lo estará a inibir o acesso ao mercado de trabalho e outras fontes de rendas, capazes de auxiliar no adimplemento das parcelas vencidas e vincendas. Logo, objetiva-se demonstrar que necessária uma mudança no nosso atual Código de Processo Civil, posto que a prisão afaste o devedor das possibilidades de pagamento das prestações alimentícias a que está incumbido.

\section{METODOLOGIA}

O artigo embasou-se em pesquisa bibliográficas e jurisprudenciais, da qual resultou a leitura e análise de leis, resoluções, doutrinas, julgados pelos tribunais e artigos. Aplicou-se o método hipotético-dedutivo, ou seja, analisando-se do geral para o particular, e confrontando as informações com uso da dialética.

\section{DA PRISÃO, ORIGEM E FINALIDADE}

A prisão tem sua origem especificamente na Idade Média, onde existiam dois tipos de prisão: a do Estado e a eclesiástica. Quanto à primeira, cabe o ensinamento do professor Bittencourt (2010), que a subdivide em duas subclassificações: a prisão-custódia, cabível como um prelúdio da verdadeira punição do réu (como por exemplo, a pena de morte) e; a detenção

\footnotetext{
${ }^{1}$ https://g1.globo.com/economia/noticia/desemprego-fica-em-128-em-julho.ghtml
} 
temporal ou perpétua. Esclarece, ainda, que essa modalidade de prisão era submetida a crimes como traição e outros crimes relacionados à política da época.

Por sua vez, o segundo tipo de prisão, a eclesiástica, era destinada a religiosos rebeldes e, diferentemente da primeira, visava demonstrar ao sujeito que nela se recolhia, que sua conduta era tida como uma afronta às normas a ele imposta, e para que, com orações se arrependesse do mal que causara (BITTENCOURT, 2010).

Em seu célebre livro Dos delitos e das penas, Cesara Breccaria ensina que (1764, p. 44):

Se o prazer e a dor são os dois grandes motores dos seres sensíveis; se, entre os motivos que determinam os homens em todas as suas ações, o supremo Legislador colocou como os mais poderosos as recompensas e as penas; se dois crimes que atingem desigualmente a sociedade recebem o mesmo castigo, o homem inclinado ao crime, não tendo que temer uma pena maior para o crime mais monstruoso, decidir-se-á mais facilmente pelo delito que lhe seja mais vantajoso; e a distribuição desigual das penas produzirá a contradição, tão notória quando frequente, de que as leis terão de punir os crimes que tiveram feito nascer. (sic)

Dessa forma, pode-se estabelecer que a principal finalidade da prisão fosse punir os crimes mais graves, tanto que esta, em consonância com o princípio penal da ultima ratio, só deve ser usada, quando todos os demais meios postos à disponibilidade do operador do Direito, se encontrarem falhos. Dessa forma, Bittencourt aduz que (2010, p. 56):

se outras formas de sanção ou outros meios de controle social revelaremse suficientes para a tutela desse bem, a sua criminalização é inadequada e não recomendável. Assim, se para o restabelecimento da ordem jurídica violada forem suficientes medidas civis ou administrativas, são estas as que devem ser empregadas, e não as penais.

Nesta toada, a prisão, em tese, serviria para punir os delitos não passíveis de solução pelas searas cíveis e administrativas, indo de encontro com a aplicabilidade de prisão civil do devedor de alimentos existente em nosso atual diploma civil.

\section{DOS ALIMENTOS}

Segundo Gomes (2002), alimentos se constituem prestações visando a satisfazerem as necessidades básicas de quem, por si só, não pode provê-las. Assim, os alimentos devem prover "o indispensável ao sustento, vestuário, habitação, assistência médica, instrução e educação (CC, arts. 1.694 e 1.920)" (GONGALVES, 2017, p. 497). Quanto a quem deve prestar alimentos, Silvio Rodrigues ensina que (2004, p. 380):

$\mathrm{Na}$ obrigação decorrente do parentesco, são chamados a prestar alimentos, em primeiro lugar, os parentes em linha reta, recaindo a obrigação nos mais próximos em grau, uns em falta dos outros. Assim, se por causa de idade ou moléstia a pessoa não pode prover a sua subsistência, deve reclamar alimentos de seu pai, avô etc. (art. 1.696), ou de seus filhos (art. 1.697). A estes, desde que o possam, incumbe fornecer os alimentos, ainda que haja netos, ou bisnetos, com recursos muito mais amplos. Não havendo filhos, são chamados os netos a prestar alimentos, e assim por diante, porque a existência de parentes mais próximos exclui os mais remotos da obrigação alimentícia. 
Restando infrutífero o pleito aos parentes consanguíneos em linha reta, o autor prossegue seus ensinamentos, dizendo que a obrigação recairá sobre os parentes colaterais em segundo grau, correspondente aos irmãos.

Azevedo (2013, p. 315) afirma que a "prestação de alimentos é recíproca entre os parentes, os cônjuges ou companheiros". Dessa forma, àqueles a quem recai a obrigação de prestar alimentos também é atribuída à faculdade de solicitá-los. Rodrigues (2004) restringe tal direito aos parentes afins, bem como os exonera da obrigação de prestá-los.

No que atine à forma como devem ser prestados os alimentos, Rizzardo, em sua obra Direito de Família, doutrina que estes devem ser (2014) "entregue em dinheiro, ou em bens e utilidades que atendam às necessidades da pessoa", cabendo ao juiz fixar a forma do cumprimento da prestação. No que concerne ao limite devido, ensina, ainda, o autor (2014):

Fixa-se a pensão proporcionalmente às necessidades do reclamante e à possibilidade do alimentante.

A necessidade é considerada em função das circunstâncias de cada caso, ou da condição econômica e social das pessoas envolvidas.

Deve-se dar realce às particularidades das pessoas envolvidas, como idade, sexo, estado de saúde, formação profissional, situação econômica, patrimônio e renda mensal.

$\mathrm{Na}$ mensuração das necessidades, levam-se em conta os encargos não apenas da subsistência, mas também os educacionais, recreativos etc.

\section{DA AÇÃO DE ALIMENTOS E SUA EXECUÇÃO}

Gonçalves (2016) elenca quatro pressupostos para constituir a obrigação alimentar: a) grau de parentesco; b) necessidade do reclamante; c) possibilidade da pessoa obrigada; e d) proporcionalidade.

A lei no 5.478 de 1968- Lei de alimentos- em seu artigo 1으, determina que esta ação possua um rito especial, e não depende de distribuição anterior, bem como de concessão da gratuidade da justiça (BRASIL, 1968). Para tanto, em inicial, o autor deve demonstrar a necessidade dos alimentos, devendo provar, apenas, o grau de parentesco ou a obrigação de alimentar do sujeito passivo, o devedor (artigo 2ㅇ).

Despachando a inicial, o juiz pode fixar, desde logo alimentos provisórios, que fixados na proporção de um terço dos vencimentos do alimentante e serão devidos até a decisão final, conforme artigo 13, §3ㅇ da Lei de Alimentos (GONÇALVES, 2016). Em seguida, ordenará a citação do réu, para que apresente contestação e agendará audiência de conciliação e mediação. Ausente, em tal audiência, o autor terá determinado o arquivamento do pedido; todavia, se o ausente for o réu, este incorrerá nos efeitos da revelia, conforme dispõe os artigos 60 e 70으, lei supracitada (BRASIL, 1968):

Art. 6 Na audiência de conciliação e julgamento deverão estar presentes autor e réu, independentemente de intimação e de comparecimento de seus representantes.

Art. 70 0 não comparecimento do autor determina o arquivamento do pedido, e a ausência do réu importa em revelia, além de confissão quanto à matéria de fato.

Se houver acordo, este será levado a termo, no entanto, restando tal conciliação infrutífera, o juiz ouvirá as partes e as testemunhas presentes, se houver, sendo-lhe facultado, se as partes assim concordarem, o julgamento da lide sem a produção de provas. Finda a instrução, as partes e o Ministério Público, se presente, terão 10 (dez) minutos cada, para realizar suas 
alegações finais; após, o juiz novamente, tentará compor acordo entre as partes e, se em negativa, prolatará sentença (BRASIL, 1968).

Tal sentença constitui título executivo judicial, nos termos do artigo 515, inciso I, do Código de Processo Civil, sendo aberto ao autor requerer o cumprimento da sentença com o rito estabelecido pelos artigos 528 e seguintes do Código de Processo Civil. Marcus Vinicius Rios Gonçalves, em sua obra Novo Curso de Direito Processual Civil, ensina que "Esse regime especial de cumprimento de sentença tem por objeto prestação de alimentos, mas não os decorrentes de atos ilícitos. Os únicos que podem ser executados na forma do art. 528 são aqueles que têm origem no direito de família, não no direito das obrigações" (2017, p. 221).

Iniciando o autor o cumprimento da sentença, o juiz intimará o executado para que, em 3 (três) dias, realize o pagamento, comprove que já o fez ou justifique a impossibilidade fazê-lo, com fulcro no artigo 528, in fine, do CPC. Não promovendo qualquer das alternativas no prazo assinalado, o juiz mandará protestar o título executivo podendo, ainda, decretar que o executado seja recolhido à prisão, por no mínimo 01 (um) e no máximo 3 (três) meses.

\section{DA PRISÃO CIVIL NO ORDENAMENTO JURÍDICO BRASILEIRO}

A Constituição Federal em seu artigo 5으, LXVII, estabelece que (BRASIL, 1988):

LXVII - Não haverá prisão civil por dívida, salvo a do responsável pelo inadimplemento voluntário e inescusável de obrigação alimentícia e a do depositário infiel;

Ainda que existam duas previsões no artigo supracitado, o Supremo Tribunal Federal entende ser admitida no ordenamento jurídico brasileiro apenas a primeira hipótese, devedor de prestação alimentícia, como se vê no voto do Min. Gilmar Mendes em sede de Recurso Extraordinário (RE no 466.343):

Enfim, desde a adesão do Brasil, no ano de 1992, ao Pacto Internacional dos Direitos Civis e Políticos (art. 11) e à Convenção Americana sobre Direitos Humanos 'Pacto de San José da Costa Rica (art. 7ำ 7), não há base legal par aplicação da parte final do art.5ำ, inciso LXVII, da Constituição, ou seja, para a prisão civil do depositário infiel.

Juntamente com a decisão da Min. Ellen Gracie, em sede de Habeas Corpus, resultou a edição da Súmula Vinculante no 25, a saber:

Súmula Vinculante no 25 - É ilícita a prisão civil de depositário infiel, qualquer que seja a modalidade de depósito.

Dessa forma, hoje no Brasil apenas o devedor de alimentos está sujeito a ter sua liberdade privada se, em 3 (três) dias, não promover o pagamento do débito alimentício, consistente nas últimas três prestações; não comprovar que o fez ou não apresentar justificativa da impossibilidade de fazê-lo.

Importante ressalvar-se que, apenas o débito de três prestações alimentares anteriores ao ajuizamento da ação autoriza a decretação da prisão, mais as que se vencerem no curso da ação, conforme dispõe a súmula 309 do STJ e §70 do art. 528, do CPC. Dessa forma, quitando tais débitos referidos acima, a prisão é revogada e o alimentante é posto em liberdade. Segundo Gonçalves (2017, p. 223)

O cumprimento da prisão não exime do pagamento da dívida que ensejou a sua decretação. Ele continuará obrigado a pagá-la, mas não poderá ser preso novamente pelas mesmas prestações, que deverão ser executadas 
na forma convencional, com penhora e expropriação de bens. Nada obsta que venha a ser preso de novo, se deixar de pagar outras parcelas.

Há discussão no âmbito jurídico sobre a eficácia de tal medida coercitiva, no que diz respeito a satisfação do crédito alimentar, segundo HERTEL (2011, p. 72) "a prisão do devedor de alimentos não ofende a dignidade da pessoa humana: ao contrário, ela preserva a vida e a dignidade do credor dos alimentos". Entende o jurista, que a aplicação da pena privativa de liberdade em nada afeta ao pleito do credor de alimento, pelo contrário, visa atender justamente seu pleito. À contramão de seu entendimento, FERREIRA $(2013$, p. 8) afirma "a prisão civil em muitos casos não garante o pagamento da prestação e, por vezes, inviabiliza que o devedor comece a contribuir em dia com as prestações alimentares as quais já foi condenado a pagar e pondera dizendo $(2013$, p. 7$)$ "o juiz poderá, na instrução da causa, ou da execução da sentença ou do acordo, tomar todas as providências necessárias para seu esclarecimento ou para o cumprimento do julgado ou do acordo, inclusive a decretação da prisão do devedor". Seguindo o mesmo raciocínio SALES (2015) afirma, "antes, deve haver medidas de restrição de crédito, com inscrição nos serviços de proteção, como Serasa e SPC".

\section{CONCLUSÃO}

Diante de todo o narrado, conclui-se que a prisão civil do devedor de alimentos em nada contribui para a satisfação do pleito do autor. Salvo raras exceções, o inadimplemento de tais prestações decorre, muitas vezes, da impossibilidade de prestá-lo, ainda mais no cenário atual, onde o desemprego atinge cerca de 27 milhões de brasileiros. Logo, a decretação de prisão, afasta ainda mais o alimentante inadimplente do mercado de trabalho e em nada possibilita a realização do adimplemento da obrigação alimentar a que está obrigado.

A prisão é e deve ser apenas instituto de direito penal, elaborado e destinado à privação da liberdade daqueles que delinquirem contra a sociedade. A aplicação de tal privação ao devedor de alimentos é descabida, à medida que não ofende os princípios do código penal e processo penal, que dispõem sobre as medidas privativas de liberdade.

Desta feita, faz se necessária alteração na legislação, assim como se alterou a prisão do depositário infiel, não se permitindo, assim, que o devedor de alimentos se sujeite de imediato, à prisão, mas se tenha métodos alternativos para solucionar este impasse, tal como ser encaminhado a cursos de qualificação profissional para que possa ser novamente, encaminhado ao mercado de trabalho, onde, com mais segurança, honrará suas dívidas, podendo, sem qualquer impedimento, o autor dos alimentos requerer a medida estabelecida no artigo 529 do Código de Processo Civil.

\section{REFERÊNCIAS}

AZEVEDO, Álvaro Villaça. Direito de família. São Paulo: Atlas, 2013.

BITTENCOURT, Cesar Roberto. Falência da pena de prisão: causas e alternativas, 4a ed. Saraiva 2010.

BRASIL. Constituição (1988). Constituição da República Federativa do Brasil: promulgada em 5 de outubro de 1988. Senado Federal, 2015.

. Supremo Tribunal Federal. Súmula no 25. É ilícita a prisão civil de depositário infiel, qualquer que seja a modalidade de depósito. Acessado em 10 jul. 2017. Disponível em: < http://www.stf.jus.br/portal/jurisprudencia/menuSumario.asp?sumula=1268> 
Supremo Tribunal Federal. EMENTA: PRISÃO CIVIL. Depósito. Depositário infiel. Alienação fiduciária. Decretação da medida coercitiva. Inadmissibilidade absoluta. Insubsistência da previsão constitucional e das normas subalternas. Interpretação do art. 5으, inc. LXVII e $\S \S 10,2$ e 3으, da CF, à luz do art. 7으, § 7, da Convenção Americana de Direitos Humanos (Pacto de San José da Costa Rica). Recurso improvido. Julgamento conjunto do RE no 349.703 e dos HCs no 87.585 e no 92.566. E ilícita a prisão civil de depositário infiel, qualquer que seja a modalidade do depósito. Recorrente: Banco Bradesco S.A. Recorrido: Luciano Cardoso Santos. Relator: Min. Cezar Peluso. Brasília, 03 de dez. de 2008. Disponível em: http://redir.stf.jus.br/paginadorpub/paginador.jsp?docTP=AC\&doclD=595444, acessado em: 10 de jul. de 2017.

Lei 5.478 de 1.968. Dispõe sobre a ação de alimentos e dá outras providências, acessado em 10 de jul. de 2017. Disponível em: http://www.planalto.gov.br/ccivil 03/leis/L5478.htm

Lei no 13.105 de 2.015. Código de Processo Civil, acessado em 13 de jul. de 2.017. Disponível em: http://www.planalto.gov.br/ccivil 03/ ato2015-2018/2015/lei/l13105.htm

BRECCARIA, Cesare. Dos delitos e das penas, acessado em 06 de jul. de 2017. Disponível em http://www.dominiopublico.gov.br/download/texto/cv000018.pdf

FERREIRA, Flávia Elaine Soares. A prisão civil do devedor de alimentos: em busca da efetividade da medida que pretende servir como coercitiva ao adimplemento da obrigação alimentar, acesso em 21 de set. de 2017. Disponível em: http://www.publicadireito.com.br/artigos/?cod=846b8bb19a1488bb

GOMES, Orlando. Direito de família. 14. ed. Atualização de Humberto Theodoro Júnior. Rio de Janeiro: Forense, 2002.

GONÇALVES. Carlos Roberto. Direito civil brasileiro: volume 6 - direito de família. 14ạ ed. São Paulo: Saraiva 2016.

GONÇALVES. Marcus Vinícius Rios. Novo curso de direito processual civil: volume 3. 10ạ ed. São Paulo: Saraiva 2017.

HERTEL, Daniel Roberto. A extinção da prisão do devedor de alimentos será a solução de que problema social?, acessado em: 21 de set. de 2017. Disponível em: www.emerj.tjrj.jus.br/revistaemerj online/edicoes/.../revista56 72.pdf.

RIZZARDO, Arnaldo. Direito de família. 9ạ ed. Rio de Janeiro: Forense, 2014.

RODRIGUES, Silvio. Direito civil: direito de família: volume 6. 28. ed. rev. e atual. por Francisco José Cahali; de acordo com o novo Código Civil (Lei n. 10.406, de 10-1-2002). - São Paulo: Saraiva, 2004.

SALES. Elaine Cristina Santos. Ação de alimentos e a prisão civil do devedor: qual a eficácia da medida, acesso em 21 set. de 2017. Disponível em: http://www.ambito- 
juridico.com.br/site/index.php?n link=revista artigos leitura\&artigo id=16885\&revista caderno= $\underline{14}$ 